\section{Der Prothesenkunststoff Paladon wird 80 Jahre alt}

Mit seiner großen Auswahl an hochwertigen Prothesenkunststoffen und -zähnen sowie Zubehör ist Pala von Heraeus Kulzer heute das Rundum-System für effektive Prothetik. Was viele nicht wissen: Pala ist auch die traditionsreichste Marke des Hanauer Dentalherstellers. Vor 80 Jahren erkannte der Zahntechniker Gottfried Roth,

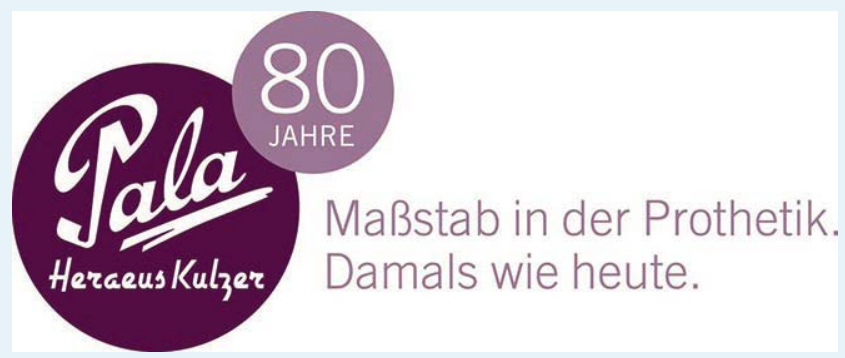

dass sich das Acrylharz Polymethylmethacrylat (PMMA) aufgrund seiner Konsistenz für die Herstellung von Zahnprothesen eignet. Mit der Patentierung durch die Firma Kulzer begann die Erfolgsgeschichte des weltweit 1. heißpolymerisierenden Prothesenkunststoffs Paladon, der bis dahin gängige Kautschukprothesen ablöste. Seine stetig weiterentwickelten mechanischen Produkteigenschaften, die das heutige Paladon 65 auszeichnen, ermöglichen eine anwenderfreundliche, variable Verar- beitung und effiziente Herstellung hochwertiger Prothesen. Pala Prothesenkunststoffe bieten für jede Anwendung die optimale Lösung. Im Laufe der Jahrzehnte hat sich Pala als Dachmarke für ganzheitliche Prothetiklösungen im Dentalmarkt immer breiter aufgestellt. Neben den Kunststoffen zählen heute die Zahnlinien Pala Premium, Pala Idealis und Pala Mondial zu den Kernprodukten der Markenfamilie. Innovationen wie die extra-dünnen PalaVeneer Verblendschalen ergänzen seit 2015 das Sortiment und sorgen für noch mehr Effizienz im Labor. „Die Erfindung von Paladon vor 80 Jahren hat den Grundstein für unser bewährtes Pala System gelegt, dem heute Dentallabore weltweit vertrauen“, so Olaf Mrotzek, Key Account Manager Zähne bei Heraeus Kulzer. „Wir freuen uns darauf, das Jubiläum gemeinsam mit unseren Kunden und Partnern zu feiern.“

Nach einer Pressemitteilung der Heraeus Kulzer GmbH, Hanau www.heraeus-kulzer.de 